
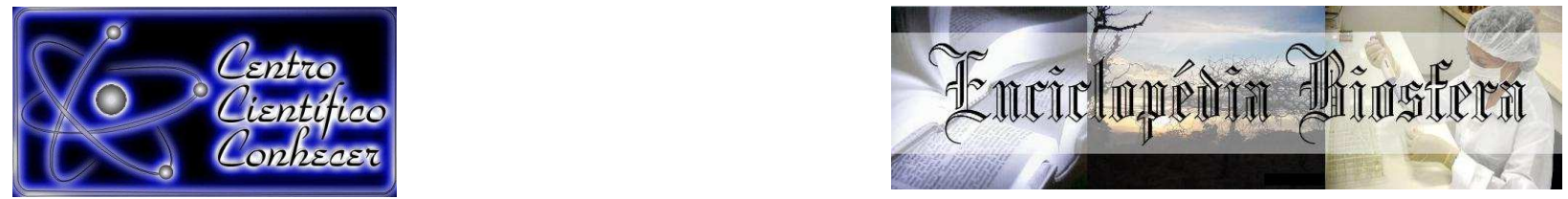

\title{
ANÁLISE AGRONÔMICA E ECONÔMICA DO CULTIVO DE MELÃO (Cucummis melo, L.) CONDUZIDO NA REGIÃO SEMIÁRIDA DO NORDESTE BRASILEIRO
}

José Aluisio de Araújo Paula'; Eudes de Almeida Cardoso ${ }^{2}$; Roberto Pequeno de Sousa ${ }^{2}$, Janilson Pinheiro de Assis ${ }^{2}$

${ }^{1}$ Eng. Agr. Doutor em Fitotecnia, Universidade Federal Rural do Semi-árido UFERSA, e-(mail: aluisiopaula@gmail.com) Mossoró-RN, Brasil

2 Eng. Agr., Doutor e professor adjunto da Universidade Federal Rural do Semi-árido - UFERSA, Mossoró-RN, Brasil

Recebido em: 02/10/2017 - Aprovado em: 21/11/2017 - Publicado em: 05/12/2017 DOI: 10.18677/EnciBio_2017B4

O melão é uma cultura importante na pauta de exportações do estado do Rio Grande do Norte, sobretudo na região do Agropolo Assú/Mossoró, localizada na Chapada do Apodí. Para alguns autores, isto ocorre devido às condições edafoclimáticas (solo, temperatura, umidade relativa do ar, etc.) e à disponibilidade de mananciais de água, de maneira que a cultura pode ser conduzida totalmente sob irrigação e receber nutrientes via fertirrigação. Neste contexto realizou-se a presente pesquisa com o objetivo de formular a análise agronômica e econômica do cultivo de melão da região semiárida do Nordeste brasileiro. O estudo foi realizado em áreas comerciais da exploração de melão na Fazenda Paulicéia, utilizando-se a média aritmética de todos os custos e receitas obtidas na exploração comercial com a cultura durante o período estudado, tendo assim, obtido uma planilha única contendo o resumo dos insumos e serviços utilizados e a média de valores de um total de área plantada de 155,48 ha, com produtividade média anual da safra de $34.414,93 \mathrm{~kg} \mathrm{ha}^{-1}$. O resultado obtido na análise agronômica dos dados do ensaio é considerado satisfatório, já que, de um modo geral, a produtividade obtida, cerca de 34 ton.ha ${ }^{-1}$, foi superior a média obtida na região produtora para o período, cerca de $30 \mathrm{Mg} \cdot \mathrm{ha}^{-1}$. A análise econômica realizada demonstrou que o preço de equilíbrio $(\mathrm{R} \$$ 7,11 por caixa) foi menor que o preço obtido na venda da produção de frutas frescas na área média analisada ( $\mathrm{R} \$ 7,37$ por caixa). De acordo com os resultados obtidos, conclui-se que, nas condições estudadas, a atividade produtora de melão demonstrou ser a mais lucrativa dentre as opções estudadas e a mais adequada para a exploração dentre as situações edafoclimáticas avaliadas.

PALAVRAS-CHAVE: custo de oportunidade, índice de rentabilidade, Lucro operacional total. 


\title{
AGRONOMIC AND ECONOMIC ANALYSIS OF MELON (Cucummis melo, L.) CULTIVATION CONDUCTED IN THE SEMI-ARID REGION OF NORTHEAST BRAZIL
}

\begin{abstract}
The Melon is an important crop in the exports of the state of Rio Grande do Norte, especially in the region of agropolo Assú/Mossoró, located in the Apodi Plateau. For some authors, this is due to environmental conditions (soil, temperature, relative humidity, etc.) and the availability of water sources, so that culture can be conducted entirely under irrigation and receive nutrients through fertigation. In this context, the present research was carried out with the objective of formulating the agronomic and economic analysis of melon cultivation in the semi-arid region of Northeast Brazil. The study was carried out in commercial areas of the melon farm in the Paulicéia Farm, using the arithmetic mean of all costs and revenues obtained in the commercial exploitation with the crop during the studied period, thus obtaining a single spreadsheet containing the summary of the inputs and services used and the average values of a total planted area of 155.48 ha, with an average annual yield of $34,414.93 \mathrm{~kg}$ ha-1. The result obtained in the agronomic analysis of the data of the test is considered satisfactory, since, in general, the productivity obtained, about 34 ton.ha-1, was higher than the average obtained in the producing region for the period, about $30 \mathrm{Mg}$.ha-1. The economic analysis carried out showed that the equilibrium price ( $R \$ 7.11$ per box) was lower than the price obtained in the sale of fresh fruit production in the medium analyzed ( $R \$ 7.37$ per box). According to the results obtained, it was concluded that, under the conditions studied, the melon production activity was the most profitable among the options studied and the most suitable for exploitation among the evaluated soil and climatic conditions.
\end{abstract}

KEYWORDS: opportunity cost, profitability index, Total operating income.

\section{INTRODUÇÃO}

O melão (Cucummis melo, L.) é uma importante cultura na pauta de exportações do estado do Rio Grande do Norte, sobretudo a região do Agropolo Assú/Mossoró, localizada na Chapada do Apodí. Isto ocorre devido às condições edafoclimáticas favoráveis (solo, temperatura, umidade relativa do ar, etc.) da região e da disponibilidade de mananciais de água superficial e subterrânea, de maneira que as culturas podem ser conduzidas totalmente sob irrigação e receber nutrientes via fertirrigação (GURGEL et al., 2010).

O melão atualmente é cultivado em mais de 52 países, tendo ocupado em 2013, uma área aproximada de 843 mil hectares e uma produção de 22,9 milhões de toneladas (FAO, 2016). A China é o principal produtor, sendo responsável por $63,02 \%$, seguida pelo Irã com $6,57 \%$, pela Índia com $4,38 \%$ e pela Espanha com $3,75 \%$ da oferta mundial. O Brasil, com $2,48 \%$ da oferta mundial, é o $7^{\circ}$ produtor mundial, com uma produção anual de 565 mil toneladas (FAO, 2016).

A região nordeste é a principal produtora de melão do Brasil (CAMPELO et al., 2014), abrange aproximadamente $87 \%$ da área cultivada e participa com $95 \%$ da produção nacional (SOUSA JUNIOR et al., 2012; DANTAS et al., 2013), tendo como maiores produtores os estados do Rio Grande do Norte (RN), Ceará (CE), Bahia (BA) e Pernambuco (PE), destacando-se o primeiro, tanto em área cultivada como em produção (IBGE, 2016; DIAS, 2014). 
A cerca da produção de melão das regiões do agropolo Assú/Mossoró ${ }^{1}(\mathrm{RN})$ e baixo Jaguaribe (CE), calcula-se que foram produzidas 484,0 mil toneladas em 2013 e cerca de $80 \%$ dessa produção foi destinada à exportação (COEX, 2016), grande parte destinando-se à Europa (COEX, 2016), e uma parcela sendo destinada ao mercado Norte-americano (USDA, 2015). O escoamento da produção de melão ocorre principalmente no segundo semestre, como forma de evitar as chuvas que, nesta região, acontecem no primeiro semestre (PAULA et al., 2011; COEX, 2016).

$\mathrm{O}$ ano safra adotado por alguns produtores da região corresponde a 13 meses, tendo início no final do inverno do ano vigente, indo até o final do inverno do ano seguinte. Já outros, preferem intercalar a rotação de culturas com a cultura do melão que é de clima tropical e, por isso, extremamente sensível ao excesso de chuvas e a ocorrência de baixas temperaturas no período do inverno da região (CRISOSTOMO et al., 2002). Pesquisas desenvolvidas em solos de aluvião do vale do Curu - CE, apontaram como saída para o problema, o plantio de arroz no $1^{\circ}$ semestre, seguidas de duas safras de melão no $2^{\circ}$ semestre (OLIVEIRA JÚNIOR et al., 1998).

No Rio Grande do Norte, a cultura do arroz, há décadas vem sendo cultivado no Vale do Apodi/RN, tendo-se como destaque os municípios de Apodi e Felipe Guerra, onde a maior parte do processo de cultivo é feito por meio de irrigação via inundação, e em menor escala, plantado em áreas de várzeas úmidas sem irrigação, tendo-se ainda a atividade basicamente sendo desenvolvida em pequenas propriedades rurais, com uso de mão de obra familiar (OLIVEIRA NETO, 2015).

Estudos revelaram que os resultados da pesquisa agronômica devem obrigatoriamente passar pelo crivo legitimador da teoria econômica, sem o qual o desempenho produtivo resultante da introdução de novas tecnologias de produção agrícola não serve de parâmetro para decisão de adotar tais inovações. E acrescentam ainda que, quando os produtos e produtores competem numa máxima esfera global de abrangência e inababilidade, os preços de mercado (de fatores e produtos) são os mais valiosos indicadores para a correta tomada de decisão nos diversos processos produtivos (PONTES et al. 2012).

Neste contexto realizou-se a presente pesquisa com o objetivo de formular a análise agronômica e econômica do cultivo de melão da região semiárida do Nordeste brasileiro.

\section{MATERIAL E MÉTODOS}

O estudo foi desenvolvido em áreas comerciais de produtores localizados na região semiárida do Nordeste brasileiro. As áreas comerciais em estudo foram conduzidas na Fazenda Paulicéia, localizada na região produtora do agropolo Assú/Mossoró ${ }^{1}$ da Chapada do Apodí, no município de Mossoró - RN, situada em

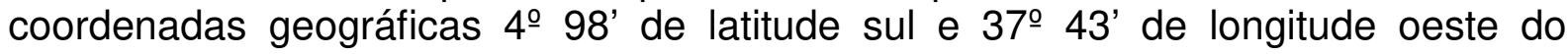
meridiano de Greenwich. Segundo classificação de Köppen, o clima dessa região é do tipo BSwh', caracterizado como quente e seco.

O levantamento de dados de produção da presente pesquisa correspondeu ao período safra de 2011/2012 que durou de março de 2011 a abril de 2012 (13 meses), e foram utilizadas tanto na formulação da proposta agronômica, quanto para a proposta econômica do ensaio.

\footnotetext{
${ }^{1}$ Para Neves (2006), a região do Agropolo Assú/Mossoró, no Rio Grande do Norte, está a oeste do Estado, na divisa com o Ceará e compreende os municípios potiguares de Mossoró, Açu, Baraúna, Carnaubais, Upanema, Ipanguaçu, Alto do Rodrigues, Afonso Bezerra, Pendências, Serra do Mel e Itajá, tem-se destacado pela sua crescente produção nessa cultura hortícola.
} 
Para a análise agronômica, realizou-se amostragem composta de solo nas profundidades de 0-20 e 20-40 que foram encaminhadas ao laboratório de solo da UFERSA onde identificou-se a composição granulométrica local do solo, tendo a análise física do solo apontado como resultado o teor de partículas moderadamente grosseira (10\% argila, $20 \%$ silte e $70 \%$ areia) ou uma textura franco-arenosa. Nela foram comparados os dados médios de produção local com os dados médios fornecidos por órgãos oficiais (COEX, 2016) e as características edafoclimáticas locais (UFERSA, 2016) com as da experiência exitosa do consorcio de melão e arroz do Vale do Curú/CE (OLIVEIRA JÚNIOR et al., 1998).

As variedades e melões exploradas durante 0 período de estudo corresponderam a: variedade amarela (com o híbrido Gold Mine, da Petoseed ${ }^{\circledR}$ ) e a variedade Cantaloupe (com o híbrido Honey Dew Orange Flesh, da Topseed ${ }^{\circledR)}$ ). As duas variedades de melões juntas responderam por cerca de $90 \%$ de toda a exploração agrícola irrigada da fazenda durante o período de estudo e os $10 \%$ restantes foram compostos pela exploração de 14,7 ha de manga e 0,3 ha de acerola, na mesma propriedade agrícola. Sabendo-se ainda que do total explorado pela cultura do melão, cerca de $99 \%$ foi realizada em cultivos do melão amarelo e cerca de $1 \%$ com o melão Cantaloupe.

A média aritmética de todos os custos e receitas foram obtidas na exploração comercial com agricultura irrigada de melão da fazenda durante o período estudado, contabilizou-se um total de plantio de 52 áreas cujo tamanho médio foi de cerca de 2,99 ha. Uma planilha única contendo o resumo dos insumos e serviços utilizados e a média de valores do total de área plantada de 155,48 ha foi obtida, com produtividade média anual da safra de $34.414,93 \mathrm{~kg} \mathrm{ha}^{-1}$ (Eq. 01). Ao final, dividiu-se os valores da planilha média pelo tamanho médio de área obtido, para a obtenção da projeção dos valores para a área de 1,0 ha.

$$
\text { Produt. total }=(\text { Quant. cxa. } \times \text { P.cxa. })+P . \text { granel }
$$

Onde: Produt.total $\rightarrow$ é a produtividade total $\left(\mathrm{kg} \cdot \mathrm{ha}^{-1}\right.$ ou $\left.\mathrm{Mg}_{\mathrm{h}} \mathrm{ha}^{-1}\right)$;

Quant.cxa. $\rightarrow$ é a quantidade de caixas por hectare (unidades. ha ${ }^{-1}$ );

$P . c x a . \rightarrow$ é o peso por caixa $(\mathrm{kg})$;

P.granel $\rightarrow$ é o peso de frutas a granel obtidas para venda no mercado local e regional $\left(\mathrm{kg} \cdot \mathrm{ha}^{-1}\right)$.

$$
\begin{gathered}
\text { Produt, total }=2.100 \times 15+2.914,93 \\
\text { Produt, total }=34.414,93 \mathrm{~kg}^{\mathrm{h}} \mathrm{ha}^{-1} \cong 34 \text { ton. } \mathrm{ha}^{-1}
\end{gathered}
$$

Para análise econômica do estudo utilizou-se a metodologia seguida por Reis (2016), tendo-se o cuidado de observar parâmetros demonstrados por Pontes (2012). A análise da renda, através de índices de resultado econômico, serviu para auferir a eficiência do administrador e da sua força de trabalho. Como taxa de juros a ser escolhida utilizou-se a taxa de retorno da melhor aplicação alternativa, e nesse caso, optou-se pela taxa Selic que é considerada a taxa básica de juros da economia cujo valor reflete a lucratividade média das atividades produtivas da economia. No Brasil, em 2012, a projeção da taxa de juros, aplicável na cobrança, restituição ou compensação dos tributos e contribuições federais, foi em média de $0,78 \%$ ao mês, aproximadamente $9,38 \%$ ao ano (RECEITA FEDERAL, 2012). Sendo assim, considerou-se como custo de oportunidade (CO), o somatório entre o custo de oportunidade do capital (COC) e custo de aluguel do terreno (CAT). Como o desembolso dos recursos é parcelado durante o ciclo produtivo, o juro incidirá sobre metade do valor total do custo fixo (CF) e metade do valor total do custo variável $(\mathrm{CV})$ computado para o ciclo, conforme demonstrado nas equações 02 e 03. 


$$
C O C=\left(\sum_{i=C F}^{C V} \frac{\text { valor (Rs) de i }}{2}\right) X\left(\frac{\text { txi,janual }}{12}\right) X M \text { êses }
$$

Onde: $C O C \rightarrow$ é o custo de oportunidade do capital $(\mathrm{R} \$)$;

valor $(R \$)$ de $i . \rightarrow$ é o índice de variação da somatória entre o custo fixo $(C F)$ e o custo variável (CV) $\left(\mathrm{R} \$\right.$. mês $\left.^{-1}\right)$;

tx.j.anual. $\rightarrow$ é a taxa de juros anual por $\operatorname{safra}^{2}\left(\%\right.$.ano $\left.{ }^{-1}\right)$;

Mêses $\rightarrow$ é o período mensal de duração da atividade econômica em estudo (unidades).

$$
\text { CAT }=\left(\frac{\text { valor (Rs) }}{2}\right) \times\left(\frac{\text { tx.j.janual }}{12}\right) \text { XMêses }
$$

Onde: $C A T \rightarrow$ é o custo de aluguel do terreno $(\mathrm{R} \$)$;

valor $R \$$. $\rightarrow$ é o valor de aluguel da terra $\left(\mathrm{R} \$ . \mathrm{mês}^{-1}\right)$;

tx.j.anual. $\rightarrow$ é a taxa de juros anual por safra ${ }^{1}\left(\%\right.$.ano $\left.{ }^{-1}\right)$;

Mêses $\rightarrow$ é o período mensal de duração da atividade econômica em estudo

(unidades).

\section{RESULTADOS E DISCUSSÃO}

Os resultados obtidos na análise agronômica dos dados do ensaio são considerados satisfatórios, já que quando comparados ao da proposta apontada para solos aluviões do Vale Curú/CE (OLIVEIRA JÚNIOR et al., 1998), os resultados da presente pesquisa demonstraram que para a região produtora da Chapada do Apodí estudada, esta não se aplica já que a maior parte das áreas exploradas com agricultura irrigada do melão da região apresentam solos de textura franco-arenosa (CRISOSTOMO et al., 2002), semelhante a textura encontrada na presente pesquisa, e por isso, inviáveis ao manejo com a cultura do arroz que é favorecida com a inundação das áreas cultivadas (OLIVEIRA NETO, 2015).

A justificativa é totalmente respaldada como a saída apontada pelos produtores da região, já que em solos com tais características encontradas, raramente se encontram em situações de inundação, ainda mais quando as informações pluviométricas locais para o ano safra 2011/2012 apontando inverno abaixo da média (registro de 449,5 mm/ano), formado por chuvas bem distribuídas durante todo o período (UFERSA, 2016). O que faz com que, com um ano/safra iniciando-se ao final do inverno do ano vigente e terminando no final do inverno do ano seguinte, consigam-se índices de produtividade tão elevadas com a cultura do melão, bastante favoráveis a utilização de áreas com a cultura estudada para todo o período (CRISOSTOMO et al., 2002).

A análise econômica realizada (tabelas 01 e 02) demonstrou que o preço de equilíbrio ( $R \$ 7,11$ por caixa) foi menor que o preço obtido na venda da produção de frutas frescas na área analisada ( $R \$ 7,37$ por caixa), isto é, as receitas seriam maiores que os custos e o produtor estaria obtendo lucro. Índice confirmado pelo ponto de nivelamento da produção que demonstrou que com o valor de $29.882,43$ $\mathrm{kg} / \mathrm{ha}$ e preço médio de $\mathrm{R} \$ 7,37$ por caixa, os custos da fazenda se igualariam as receitas, tendo a fazenda, neste ano safra obtido produtividade de $34.414,93 \mathrm{~kg} / \mathrm{ha}$, apresentando índice de lucratividade (IL) de 2,79\%.

Pode-se afirmar ainda que, para esse ano safra, a remuneração que o produtor obteve com seu trabalho ( $\mathrm{R} \$ 341,22 / \mathrm{ha}$ ) superou o custo de oportunidade que seria obtido com as aplicações financeiras do capital e aluguel da terra ( $R \$ 127,83 / \mathrm{ha})$ em cerca de 2,7 vezes.

\footnotetext{
${ }^{2}$ Medida pela taxa selic conforme recomenda Receita Federal (2012).
} 
Paulino et al. (1994), em estudo semelhante com a cultura do melão, para a região de Ilha Solteira (SP), concluíram que apesar do alto valor do investimento inicial, a cultura se mostrou altamente rentável e que o resultado econômico, gerado pela diferença entre a receita bruta e o custo total, recebe influência direta dos níveis de produtividade e do preço alcançado pelo produto.

De um modo geral, a produtividade obtida, cerca de 34 ton.ha ${ }^{-1}$, foi superior a média obtida na região produtora para o período, cerca de $30 \mathrm{Mg} \mathrm{ha}^{-1}$ (COEX, 2016), pode-se acrescentar ainda que, com tal eficiência obtida no sistema produtivo, apostar em outras opções de exploração da terra seria o mesmo que assumir riscos desnecessários somente justificados se todos os índices econômicos supra mencionados tivessem dado valores invertidos.

\section{CONCLUSÕES}

De acordo com os resultados obtidos, conclui-se que, nas condições estudadas, a atividade produtora de melão demonstrou ser a mais lucrativa dentre as opções estudadas e a mais adequada para a exploração dentre as situações edafoclimáticas avaliadas.

\section{REFERÊNCIAS}

CAMPELO, A. R.; AZEVEDO, B. M.; NASCIMENTO NETO, J. R.; VIANA, T. VA.; PINHEIRO NETO, L. G.; LIMA, R. H. Manejo da cultura do melão submetida a frequência de irrigação e fertirrigação com nitrogênio. Horticultura Brasileira, v. 32, n. 2, p. 138-144, 2014.

COEX - Comitê Executivo de Fitossanidade do Rio Grande do Norte - Dados de exportação de melão: Período de 2013 a Março/2016. Mossoró: 2016, 2 f.

CRISÓSTOMO, L. A.; SANTOS, A. A.; FARIA, C. M. B.; et al. Adubação, Irrigação, Híbridos e Práticas Culturais para o Meloeiro no Nordeste. Fortaleza: Embrapa Agroindústria Tropical, 2002. 21 p. (Circular Técnica, 14).

DANTAS, I. C.; OLIVEIRA, C. W.; SILVA, F. L.; SANTOS, F. S. S.; MARCO, C. A. Produção de melão amarelo sob diferentes densidades de plantio. Revista Brasileira de Agricultura Irrigada, v. 7, n. 1, p. 74-84, 2013.

DIAS, V. G. Crescimento, fisiologia e produção do meloeiro "pele de sapo" cultivado sob diferentes lâminas de irrigação. Campina Grande, Universidade Estadual da Paraíba, 2014. 84f. (Dissertação de Mestrado em Ciências Agrárias).

FAO. FAOSTAT Database Results, maintained by FAO, Roma. Disponível em: <http://apps.fao.org>. Acesso em: 01 jan. 2016.

GURGEL, M. T.; UYEDA, C. A.; GHEYI, H. R.; OLIVEIRA, F. H. T.; Fernandes, P. D.; Silva, F. V. Crescimento de meloeiro sob estresse salino e doses de potássio. Revista Brasileira de Engenharia Agrícola e Ambiental, v.14, p.3-10, 2010.

IBGE. Instituto Brasileiro de Geografia e Estatística. (2011). Estados@. Disponível em: 
$<$ http://www.gov.br/estadosat/temas.php?sigla=rn\&tema=lavouratemporaria2011>. Acesso em: 10 dez. 2016.

NEVES, M. C. M. Qual a melhor região para investir em fruticultura? Hortifruti Brasil, [s.I], v. 44, 9p. Março. 2006. Disponível em: <http://www.cepea.esalq.usp.br/hfbrasil>. Acesso em: 01 set. 2006.

OLIVEIRA JÚNIOR, N. M.; COSTA, R. N. T.;SAUNDERS, L. C. U.; BISERRA, J. V. Análise econômico-comparativa de planos de cultivo em um solo sódico submetido a um manejo integrado de recuperação. Revista Brasileira de Engenharia Agrícola e Ambiental, Campina Grande, v.2, n.2, p.165-169, 1998.

OLIVEIRA NETO, A. A. (Org.). A cultura do Arroz. Brasília: CONAB, 2015. 180 p.

PAULA, J. A. A; MEDEIROS, J. F; ESPÍNOLA SOBRINHO, J; CARDOSO, E. A; MENDONÇA, V. Sistema informatizado para o manejo da irrigação na cultura da mangueira cv. 'tomy atkins' para a chapada do apodi. Agropecuária Científica no Semi-Árido, v.7, n. 4, p. $01-$ 04, 2011.

PAULINO, H. B.; TARSITANO, M. A. A.; HERNANDEZ, F.B.T.; BUZETTI, S. Viabilidade econômica da cultura do melão (Cucumis melo L.) na região de ilha solteira - sp. Sciêntia Agricultural, Piracicaba, v.51, n.2, p.519-523, 1994.

PONTES, F. S. T. Apontamentos de aula da disciplina de Análise Econômica de Experimentos Agropecuários. s/e. UFERSA/PPGF, Mossoró, s/v, 26p. 2012.

RECEITA FEDERAL. Taxa selic. Disponível em: <http://www.receita.gov.br/Pagamentos/jrselic.htm\#Taxa_de_Juros.....Selic> Acesso em: 15 de jun. de 2012.

REIS, R. P. Fundamentos de Economia Aplicada. s/e. Lavras: UFLA/FAEPE, s/v, 95p. (Textos Acadêmicos). Disponível em: <http://www.ufla.edu.br>. Acesso em: 01 set. 2016.

SOUZA JÚNIOR, R. F.; OLIVEIRA, F. H. T.; SANTOS, H. C.; FREIRE, F. J. ARRUDA, J. A. Frações de fósforo inorgânico do solo e suas correlações com o fósforo quantificado por extratores e pelo milho. Revista Brasileira de Ciência do Solo, v. 36, n. 1, p. 159-169, 2012.

UFERSA - Universidade Federal Rural do Semi-Árido. Planilha Excel com registros pluviométricos da estação meteorológica Jerônimo Rosado da UFERSA em Mossoró/RN: Período de 1998 a 2012. Mossoró:UFERSA. 2016, 2p.

USDA. The U.S. and World Situation: Melons. USDA Foreign Agricultural Service Horticultural \& Tropical Products. Disponível em: <http://www.fas.usda.gov>. Acesso em: 01 set. 2015. 
Tabela 1 - Análise econômica com a composição dos custos fixos e custos variáveis do estudo realizado na Chapada do Apodí, Mossoró-RN, para o período safra de $2011 / 2012$.

\begin{tabular}{|c|c|c|c|c|c|}
\hline \multirow[b]{2}{*}{ COMPONENTES } & \multirow[b]{2}{*}{ Unidade } & \multirow[b]{2}{*}{ Quantidade } & \multicolumn{2}{|c|}{$\mathrm{R} \$$ /Safra $2000-2001$} & \multirow[b]{2}{*}{$(\%)$} \\
\hline & & & $\begin{array}{l}\text { Valor Unitário } \\
\quad(\mathrm{R} \$)\end{array}$ & Valor total & \\
\hline A. CUSTOS VARIÁVEIS (CV) & & & & $\mathbf{R} \$ 13.229,77$ & $81,05 \%$ \\
\hline A.1. Insumos & & & & $\mathrm{R} \$ 10.441,89$ & $63,97 \%$ \\
\hline A.1.1.Uso de Inseticidas & $\mathrm{kg}$ ou L & 11,87 & 156,83 & $\mathrm{R} \$ 1.861,57$ & $11,41 \%$ \\
\hline A.1.2.Uso de fungicidas, bactericida e viricida & $\mathrm{kg}$ ou L & 27,98 & 51,31 & $\mathrm{R} \$ 1.435,65$ & $8,80 \%$ \\
\hline A.1.3.Nutrição foliar e espalhantes adesivos & $\mathrm{kg}$ ou L & 68,94 & 6,33 & $\mathrm{R} \$ 436,39$ & $2,67 \%$ \\
\hline A.1.4.Nutrição com macronutrientes e matéria orgânica & $\mathrm{kg}_{\text {ou m}}{ }^{3}$ & $2.498,04$ & 0,79 & $\mathrm{R} \$ 1.973,45$ & $12,09 \%$ \\
\hline A.1.5.Sementes de melão gold mine e Honey Dew Orange Flesh & unid & 15.967 & 0,08 & $\mathrm{R} \$ 1.293,33$ & $7,92 \%$ \\
\hline $\begin{array}{l}\text { A.1.6.Compra de embalagens de papelão e frete do transporte das } \\
\text { frutas até os mercados atacadistas }\end{array}$ & $\mathrm{kg}$ & $34.414,93$ & 0,10 & $\mathrm{R} \$ 3.441,49$ & $21,08 \%$ \\
\hline A.2. Mão-de-obra & & & & $\mathrm{R} \$ 638,47$ & $3,91 \%$ \\
\hline A.2.1.Adubação de Fundação & dia & 0,34 & 5,70 & $\mathrm{R} \$ 1,94$ & $0,01 \%$ \\
\hline A.2.2.Balizamento & dia & 0,5 & 5,70 & $\mathrm{R} \$ 2,85$ & $0,02 \%$ \\
\hline A.2.3.Capina & dia & 10,97 & 5,70 & $\mathrm{R} \$ 62,53$ & $0,38 \%$ \\
\hline A.2.4.Colheita & dia & 15,94 & 5,70 & $\mathrm{R} \$ 90,86$ & $0,56 \%$ \\
\hline A.2.5.Desbaste & dia & 1,4 & 5,70 & $\mathrm{R} \$ 7,98$ & $0,05 \%$ \\
\hline A.2.6.Embalagem & dia & 35,05 & 5,70 & $\mathrm{R} \$ 199,79$ & $1,22 \%$ \\
\hline A.2.7.Esterco & dia & 1,97 & 5,70 & $\mathrm{R} \$ 11,23$ & $0,07 \%$ \\
\hline A.2.8.Irrigação e Fertirrigação & dia & 23,41 & 5,70 & $\mathrm{R} \$ 133,44$ & $0,82 \%$ \\
\hline A.2.9.Plantio & dia & 3,31 & 5,70 & $\mathrm{R} \$ 18,87$ & $0,12 \%$ \\
\hline A.2.10.Preparo de área & dia & 6,18 & 5,70 & $\mathrm{R} \$ 35,23$ & $0,22 \%$ \\
\hline A.2.11.Pulverização Costal & dia & 3,2 & 5,70 & $\mathrm{R} \$ 18,24$ & $0,11 \%$ \\
\hline A.2.12.Pulverização com Trator & h.e. & 41,24 & 1,16 & $\mathrm{R} \$ 47,84$ & $0,29 \%$ \\
\hline A.2.13.Replantio & dia & 1,35 & 5,70 & $\mathrm{R} \$ 7,70$ & $0,05 \%$ \\
\hline A.3. Mecanização agrícola & & & & $R \$ 658,07$ & $4,03 \%$ \\
\hline A.3.1.Arado e sulcamento & $\mathrm{h} / \mathrm{t}$ & 6,71 & 19,27 & $\mathrm{R} \$ 129,30$ & $0,79 \%$ \\
\hline A.3.2.Cobertura & $\mathrm{h} / \mathrm{t}$ & 1,36 & 19,27 & $\mathrm{R} \$ 26,21$ & $0,16 \%$ \\
\hline A.3.3.Colheita & $\mathrm{h} / \mathrm{t}$ & 11,99 & 19,27 & $\mathrm{R} \$ 231,05$ & $1,42 \%$ \\
\hline A.3.4.Fundação & $\mathrm{h} / \mathrm{t}$ & 3,11 & 19,27 & $\mathrm{R} \$ 59,93$ & $0,37 \%$ \\
\hline A.3.5.Gradagem e estercagem & $\mathrm{h} / \mathrm{t}$ & 3,36 & 19,27 & $\mathrm{R} \$ 64,75$ & $0,40 \%$ \\
\hline A.3.6.Pulverização & $\mathrm{h} / \mathrm{t}$ & 7,62 & 19,27 & $\mathrm{R} \$ 146,84$ & $0,90 \%$ \\
\hline A.4. Energia elétrica & & & & $\mathrm{R} \$ 1.491,34$ & $9,14 \%$ \\
\hline $\begin{array}{l}\text { A.4.1.Bombeamento da água e iluminação de galpão de embalagens, } \\
\text { casa de bombas e casa de moradores da fazenda }\end{array}$ & mês ${ }^{*}$ & 2 & 745,67 & $\mathrm{R} \$ 1.491,34$ & $9,14 \%$ \\
\hline B. CUSTOS FIXOS (CF) & & & & $\mathrm{R} \$ 3.092,41$ & $18,95 \%$ \\
\hline B.1. Mão-de-obra fixa & & & & $R \$ 906,40$ & $5,55 \%$ \\
\hline B.1.1.Mão-de-obra de auxiliares de campo & dia & 80 & 3,36 & $\mathrm{R} \$ 268,80$ & $1,65 \%$ \\
\hline B.1.2.Custo administrativo & dia & 80 & 7,97 & $\mathrm{R} \$ 637,60$ & $3,91 \%$ \\
\hline B.2. Impostos e taxas & & & & $\mathrm{R} \$ 2.026,99$ & $12,42 \%$ \\
\hline B.2.1.Custo com Impostos & mês* & 2 & $1.008,50$ & $\mathrm{R} \$ 2.016,99$ & $12,36 \%$ \\
\hline B.2.2.Imposto Territorial Rural & ha & 1 & 10,00 & $\mathrm{R} \$ 10,00$ & $0,06 \%$ \\
\hline \multirow[t]{2}{*}{ B.3. Depreciação } & & & & $\mathrm{R} \$ 159,01$ & $0,97 \%$ \\
\hline & Vida util/mês & Valor & Meses* & Deprciação & $(\%)$ \\
\hline B.3.1.Itens de fonte de água do calcário arenito-açú & 605 & $5.788,53$ & 2,00 & $\mathrm{R} \$ 19,14$ & $0,12 \%$ \\
\hline B.3.2.Itens de fonte de água do calcário dolomítico & 605 & 482,38 & 2,00 & $\mathrm{R} \$ 1,59$ & $0,01 \%$ \\
\hline B.3.3.Galpões & 600 & 347,31 & 2,00 & $\mathrm{R} \$ 1,16$ & $0,01 \%$ \\
\hline B.3.4.Tratores & 120 & $1.041,93$ & 2,00 & $\mathrm{R} \$ 17,37$ & $0,11 \%$ \\
\hline B.3.5.Casa de moradores & 240 & $1.331,36$ & 2,00 & $\mathrm{R} \$ 11,09$ & $0,07 \%$ \\
\hline B.3.6.Mangueira de polietileno com gotejadores e conexões & 60 & $3.260,00$ & 2,00 & $\mathrm{R} \$ 108,67$ & $0,67 \%$ \\
\hline C. CUSTOS OPERACIONAIS TOTAIS (COpT) & & & & $\mathrm{R} \$ 16.322,18$ & $100,00 \%$ \\
\hline
\end{tabular}

* - para efeito de cálculos, considerou-se 01 ciclo da cultura com duração de 60 dias ou 02 meses. 
Tabela 2 - Análise econômica com a composição dos indicadores econômicos do estudo realizado na Chapada do Apodí, Mossoró-RN, para o período safra de $2011 / 2012$.

\begin{tabular}{|c|c|c|c|c|c|}
\hline \multirow[b]{2}{*}{ COMPONENTES } & \multirow[b]{2}{*}{ Unidade } & \multirow[b]{2}{*}{ Quantidade } & \multicolumn{2}{|c|}{$\mathrm{R} \$ /$ Safra $2000-2001$} & \multirow[b]{2}{*}{$(\%)$} \\
\hline & & & $\begin{array}{l}\text { Valor Unitário } \\
\quad(\mathrm{R} \$)\end{array}$ & Valor total & \\
\hline D. RECEITAS BRUTA TOTAIS (RBT) & & & & $\mathrm{R} \$ 16.791,23$ & $100,00 \%$ \\
\hline $\begin{array}{l}\text { D.1. Venda de frutas encaixadas para os mercados nacionale } \\
\text { internacional }\end{array}$ & caixa & $2.100,00$ & 7,51 & $\mathrm{R} \$ 15.771,00$ & $93,92 \%$ \\
\hline D.2. Venda de frutas a granel para os mercados local e regional & $\mathrm{kg}$ & $2.914,93$ & 0,35 & $\mathrm{R} \$ 1.020,23$ & $6,08 \%$ \\
\hline $\begin{array}{l}\text { D.3. Preço médio alcançado com a venda de frutas frescas da } \\
\text { fazenda }(\mathrm{PMeA}) * *\end{array}$ & caixa & & 7,37 & & \\
\hline E. LUCRO OPERACIONAL TOTAL (LOpT) & & & & $\mathrm{R} \$ 469,05$ & \\
\hline F. ÍNDICE DE RENTABILIDADE (IR) & & & & 1,03 & \\
\hline G. ÍNDICE DE LUCRATIVIDADE (IL) & & & & $2,79 \%$ & \\
\hline H. PREÇO DE EQUILÍBRIO (PE) & & & & $\mathrm{R} \$ 7,11$ & \\
\hline I. PONTO DE NIVELAMENTO (PN) & & & & $29.882,43$ & \\
\hline J. CUSTO DE OPORTUNIDADE (CP) & & & & $\mathrm{R} \$ 127,83$ & $100,00 \%$ \\
\hline \multirow[t]{2}{*}{ J.1. Custo de oportunidade do capital (COC) } & & & & $\mathrm{R} \$ 127,64$ & $99,85 \%$ \\
\hline & valor $(\mathrm{R} \$)$ & $\begin{array}{c}\text { taxa juros anual- } \\
\text { safra*** }\end{array}$ & Meses* & Valor por safra & $(\%)$ \\
\hline J.1.1.Custo de oportunidade fixo (COF) & $\mathrm{R} \$ 1.546,20$ & $9,38 \%$ & 2,00 & $\mathrm{R} \$ 24,18$ & $18,92 \%$ \\
\hline J.1.2.Custo de oportunidadevariável (COV) & $\mathrm{R} \$ 6.614,89$ & $9,38 \%$ & 2,00 & $\mathrm{R} \$ 103,46$ & $80,93 \%$ \\
\hline \multirow[t]{3}{*}{ J.2. Custo de Aluguel do Terreno (CAT) } & & & & $\mathrm{R} \$ 0,19$ & $0,15 \%$ \\
\hline & valor $(\mathrm{R} \$)$ & $\begin{array}{l}\text { taxa juros anual- } \\
\text { safra*** }\end{array}$ & Meses* & Valor por safra & \\
\hline & $\mathrm{R} \$ 12,00$ & $9,38 \%$ & 2,00 & $\mathrm{R} \$ 0,19$ & $0,15 \%$ \\
\hline L. REMUNERAÇÃO DO TRABALHO EMPRESARIAL (RTE) & & & & $\mathbf{R} \$ 341,22$ & \\
\hline
\end{tabular}

* - para efeito de cálculos, considerou-se 01 ciclo da cultura com duração de 60 dias ou 02 meses;

** - o preço médio alcançado com frutas frescas na fazenda foi calculado através da média ponderada entre o preço obtido na venda de frutas encaixadas e a venda de frutas a granel (transformado para caixa), supondo o peso médio por caixa igual a $15 \mathrm{~kg}$; e

*** - utilizou-se como taxa de juros anuais safra a taxa SELIC, conforme recomenda a Receita Federal, para o ano de 2012. 